\title{
Effects of functional pasta ingredients on different gut microbiota as revealed by TIM-2 in vitro model of the proximal colon
}

\author{
Citation for published version (APA):
}

Martina, A., Felis, G. E., Corradi, M., Maffeis, C., Torriani, S., \& Venema, K. (2019). Effects of functional pasta ingredients on different gut microbiota as revealed by TIM-2 in vitro model of the proximal colon. Beneficial Microbes, 10(3), 301-313. https://doi.org/10.3920/BM2018.0088

Document status and date:

Published: 01/01/2019

DOI:

10.3920/BM2018.0088

Document Version:

Publisher's PDF, also known as Version of record

\section{Document license:}

Taverne

Please check the document version of this publication:

- A submitted manuscript is the version of the article upon submission and before peer-review. There can be important differences between the submitted version and the official published version of record.

People interested in the research are advised to contact the author for the final version of the publication, or visit the DOI to the publisher's website.

- The final author version and the galley proof are versions of the publication after peer review.

- The final published version features the final layout of the paper including the volume, issue and page numbers.

Link to publication

\footnotetext{
General rights rights.

- You may freely distribute the URL identifying the publication in the public portal. please follow below link for the End User Agreement:

www.umlib.nl/taverne-license

Take down policy

If you believe that this document breaches copyright please contact us at:

repository@maastrichtuniversity.nl

providing details and we will investigate your claim.
}

Copyright and moral rights for the publications made accessible in the public portal are retained by the authors and/or other copyright owners and it is a condition of accessing publications that users recognise and abide by the legal requirements associated with these

- Users may download and print one copy of any publication from the public portal for the purpose of private study or research.

- You may not further distribute the material or use it for any profit-making activity or commercial gain

If the publication is distributed under the terms of Article $25 \mathrm{fa}$ of the Dutch Copyright Act, indicated by the "Taverne" license above, 


\title{
Effects of functional pasta ingredients on different gut microbiota as revealed by TIM-2 in vitro model of the proximal colon
}

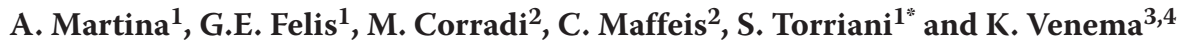 \\ ${ }^{1}$ Department of Biotechnology, University of Verona, Strada le Grazie 15, 37134 Verona, Italy; ${ }^{2}$ Unit of Pediatric Diabetes \\ and Metabolic Diseases, Regional Center for Pediatric Diabetes, Department of Surgical Sciences, Dentistry, Gynecology \\ and Pediatrics, University of Verona, P.le Stefani, 1, 37126 Verona, Italy; ${ }^{3}$ Maastricht University - campus Venlo, Centre for \\ Healthy Eating and Food Innovation, NUTRIM School of Nutrition and Translational Research in Metabolism, St. Jansweg \\ 20, 5928 RC Venlo, the Netherlands; ${ }^{4}$ Beneficial Microbes Consultancy, Johan Karschstraat 3, 6709 TN Wageningen, the \\ Netherlands; sandra.torriani@univr.it
}

Received: 5 July 2018 / Accepted: 21 November 2018

(c) 2019 Wageningen Academic Publishers

RESEARCH ARTICLE

\begin{abstract}
Diet-related modulation of gut microbiota and its metabolic activity represents an intriguing research context, particularly in the case of disorders related to imbalances in gut microbial communities. We here explored the effects of Bacillus coagulans GBI-30, 6086 (BC30), $\beta$-glucans, and innovative whole-grain pastas, with or without these functional ingredients, on gut microbiota from three groups of children, presenting different susceptibility to type 1 diabetes, by using the well-controlled TNO in vitro model of the proximal colon (TIM-2). Short- and branched-chain fatty acids production and microbiota composition were assessed by means of gas chromatography and 16S rRNA gene profiling, respectively. In most cases, in vitro dietary interventions caused microbiota-dependent modulations as a result of intergroup variability, but also specific changes in microbial groups were shared between the three microbiotas, highlighting specific diet-microbial taxa connections.
\end{abstract}

Keywords: $\beta$-glucans, Bacillus coagulans GBI-30, 6086, whole-grain pastas, gut microbiota, type 1 diabetes

\section{Introduction}

Diet is one of the key elements involved in modulation of gut microbiota composition and activity, which in turn have an impact on the health status. Diet can be intended at different levels, from dietary patterns (e.g. Western diet vs vegetarian diets), to specific foods (e.g. whole-grain products) or certain food constituents (e.g. dietary fibres, fat or proteins) (Graf et al., 2015). In this perspective, the development of functional foods able to specifically act on the gut microbiota thereby improving the overall individual well-being, i.e. foods including prebiotics or probiotics, is an attractive emerging area (Bosscher et al., 2009) both for food industries and clinicians.

In order to gain preliminary information about the effects of a new functional food, an in vitro step could be particularly useful prior to an in humana assessment, which could provide detailed information on specific mechanisms of action (Williams et al., 2015).

The TNO in vitro model of the proximal colon (TIM-2) (Minekus et al., 1999) is a system that accurately mimics the conditions in the human large intestine, being maintained under well-defined controlled parameters (temperature, $\mathrm{pH}$, and anaerobiosis). It can be inoculated with faecal material from subjects of interest, thus representing a powerful tool to study the effects of the administration of different substrates on gut microbiota, under standardised conditions (Venema et al., 2000).

In a previous research from our group, a novel functional whole-grain pasta containing a spore-forming probiotic bacterium, Bacillus coagulans GBI-30, 6086 (GanedenBC30, hereafter BC30) and $\beta$-glucans from barley was developed (Fares et al., 2015). The beneficial effects of the single 
functional ingredients on gut microbiota have been shown in some models and human studies (Cloetens et al., 2012; Nyangale et al., 2015). However, the effects of the consumption of the overall functional pasta on gut microbiota composition have not been explored yet.

Here, an in vitro study with TIM-2 was conceived to investigate the effects of the functional ingredients (BC30 and $\beta$-glucans, tested separately or in combination) and of different newly developed whole-grain pastas (the pasta containing both functional components, the pasta with $\mathrm{BC} 30$ only, and the pasta without the two ingredients) on standardised microbiota, by comparing the obtained outcomes. Faecal samples obtained from children with different susceptibility to Type 1 diabetes (T1D) (i.e. healthy, pre-diabetic and diabetic children) represented the case study microbiota. T1D is an autoimmune disorder in which dysbiosis has been reported in association with the development of the pathology (Bibbò et al., 2017; Needell and Zipris, 2016).

The assessment of the effects of the treatments was performed through gas chromatography and $16 \mathrm{~S}$ rRNA gene profiling for determining short- and branched-chain fatty acid production and microbiota composition, respectively. In order to reveal the relationship between tested dietary interventions and gut microbiota modulations, bacterial diversity within and among microbiotas from the three groups of children, and inference of the metabolic capabilities associated with the bacterial microbiomes were investigated. The utilisation of TIM-2 model revealed useful information about specific effects of the tested interventions on the gut microbiota components.

\section{Materials and methods}

\section{Intervention meals and SIEM control}

A Standard Ileal Efflux Medium (SIEM) was used as a control substrate. The composition of this medium was partially modified from previous descriptions (Gibson et al., 1988; Maathuis et al., 2009). Briefly, it contains TBCO [mixture of Tween 80 (33.4 g/l), casein $(46.5 \mathrm{~g} / \mathrm{l})$, bactopeptone $(46.5 \mathrm{~g} / \mathrm{l})$, and ox bile $(0.8 \mathrm{~g} / \mathrm{l})]$, $\mathrm{CHO}$ [mixture of pectin $(5.9 \mathrm{~g} / \mathrm{l})$, xylan $(5.9 \mathrm{~g} / \mathrm{l})$, arabinogalactan $(5.9 \mathrm{~g} / \mathrm{l})$, amylopectin $(5.9 \mathrm{~g} / \mathrm{l})$, and starch $(49.6 \mathrm{~g} / \mathrm{l})], \mathrm{MgSO}_{4} \cdot \mathrm{H}_{2} \mathrm{O}$ $(0.5 \mathrm{~g} / \mathrm{l})$, cysteine hydrochloride $(0.2 \mathrm{~g} / \mathrm{l})$, plus $1 \mathrm{ml}$ of a vitamin solution containing: menadione $(1 \mathrm{mg} / \mathrm{l})$, D-biotin (2 mg/l), vitamin B12 $(0.5 \mathrm{mg} / \mathrm{l})$, pantothenate $(10 \mathrm{mg} / \mathrm{l})$, nicotinamide ( $5 \mathrm{mg} / \mathrm{l}), \mathrm{p}$-aminobenzoic acid $(5 \mathrm{mg} / \mathrm{l})$, and thiamine $(4 \mathrm{mg} / \mathrm{l})$, plus $20 \mathrm{ml}$ of a salt solution containing: $\mathrm{K}_{2} \mathrm{HPO}_{4} \cdot 3 \mathrm{H}_{2} \mathrm{O}(156.3 \mathrm{~g} / \mathrm{l}), \mathrm{NaCl}(281.3 \mathrm{~g} / \mathrm{l}), \mathrm{CaCl}_{2} \cdot 2 \mathrm{H}_{2} \mathrm{O}$ $(28.1 \mathrm{~g} / \mathrm{l}), \mathrm{FeSO}_{4} \cdot 7 \mathrm{H}_{2} \mathrm{O}(0.31 \mathrm{~g} / \mathrm{l})$, haemine $(0.63 \mathrm{~g} / \mathrm{l})$.

To this standard medium, the specific ingredients of interest were added and in particular: (1) a freeze-dried spore preparation of BC30 (Ganeden, Mayfield Heights, OH, USA), a safe strain as testified by the GRAS status recognised from FDA (Salvetti et al., 2016), in a dose of $10^{10} \mathrm{cfu} /$ day; (2) $\beta$-glucans (purity $>94 \%$ ) (Megazyme, Bray, Ireland) in a dose of $4 \mathrm{~g} /$ day; (3) the combination of $\mathrm{BC} 30$ and $\beta$-glucans ( $10^{10} \mathrm{cfu} /$ day and $4 \mathrm{~g} /$ day, respectively); (4) the whole-grain pasta described by Fares et al. (2015) (about $27 \mathrm{~g} /$ day) (WGP); (5) a simulated pasta with BC30, obtained by adding this strain $\left(10^{10} \mathrm{cfu}\right.$ /day) to the WGP (about $27 \mathrm{~g} /$ day); (6) the innovative whole-grain pasta with BC30 and $\beta$-glucans (Fares et al., 2015) (INNP). Pasta samples were cooked in water with $1 \% \mathrm{NaCl}$, and subsequently homogenised with a domestic blender. The meal with the INN pasta and an aliquot of the one containing the WG pasta were diluted with water (50:50) to avoid technical problems due to the high viscosity of the medium, thus obtaining a final amount of pasta of about $13.5 \mathrm{~g} /$ day. The diluted INN pasta and WG pasta are hereafter referred to as dINNP and dWGP, respectively.

\section{Microbiota origin and preparation of faecal homogenates}

Two healthy children, two children at risk for T1D diabetes and two children with T1D were recruited at the Unit of Pediatric Diabetes and Metabolic Diseases, Regional Center for Pediatric Diabetes, Department of Surgical Sciences, Dentistry, Gynecology and Pediatrics, University of Verona, Italy. They participated in a previous study (Maffeis et al., 2016) conducted in accordance with the 1975 Declaration of Helsinki as revised in 2008. The protocol was approved by the Institutional Ethics Committee of Verona (Italy). The children, all males, did not use antibiotics, prebiotics, or probiotics for at least 3 months prior to the donation.

Fresh faecal samples were collected by parents in a closed box with an anaerobic strip (AnaeroGen, Oxoid, Cambridge, UK) and delivered to the laboratory, where they were snap-frozen in liquid nitrogen and stored at $-80^{\circ} \mathrm{C}$. After thawing, faecal samples for each couple of children (healthy, pre-diabetic and diabetic) were pooled in an anaerobic cabinet. In particular, faecal donations were diluted in a ratio of 1:1 in a physiological saline preparation/ dialysate (content per litre: $2.5 \mathrm{~g} \mathrm{~K}_{2} \mathrm{HPO}_{4} \cdot 3 \mathrm{H}_{2} \mathrm{O}, 4.5 \mathrm{~g} \mathrm{NaCl}$, $0.005 \mathrm{~g} \mathrm{FeSO}_{4} \cdot 7 \mathrm{H}_{2} \mathrm{O}, 0.05 \mathrm{~g}$ ox-bile), with glycerol added $(10 \% \mathrm{w} / \mathrm{w})$ as a cryoprotective agent, and this mix was homogenised with a Turrax (IKA Ultra turrax T25 digital, Staufen, Germany). Aliquots of the faecal homogenates were snap-frozen in liquid nitrogen and stored at $-80^{\circ} \mathrm{C}$ until use. Before being introduced into the system, the homogenate was thawed through a $1 \mathrm{~h}$ immersion in a $37^{\circ} \mathrm{C}$ water bath.

\section{TIM-2 experiments}

The TIM-2 system has been described previously in detail (Maathuis et al., 2009). Briefly, the system was maintained under anaerobic conditions, at $37^{\circ} \mathrm{C}$ and at a pH value of 
5.8, with peristaltic movements performed regularly. All parameters were computer-controlled.

A dialysate system consisting of a semi-permeable hollow membrane ran through the lumen, in order to remove water and fermentation products from the lumen. A dialysate solution was flushed through the membrane at a speed of $1.5 \mathrm{ml} / \mathrm{min}$, and it consisted of the physiological saline preparation described in the previous section, plus $\mathrm{MgSO}_{4} \cdot \mathrm{H}_{2} \mathrm{O}(0.5 \mathrm{~g} / \mathrm{l}), \mathrm{CaCl}_{2} \cdot 2 \mathrm{H}_{2} \mathrm{O}(0.45 \mathrm{~g} / \mathrm{l})$, cysteine hydrochloride $(0.4 \mathrm{~g} / \mathrm{l})$, and $0.1 \%$ of the vitamin solution described in the section 'intervention meals and SIEM control'.

At the beginning of each experiment, about $60 \mathrm{ml}$ of faecal homogenate were inoculated in the system together with $60 \mathrm{ml}$ of dialysate, in order to obtain a final volume of approximately $120 \mathrm{ml}$. After the inoculation of the microbiota, the above described SIEM medium was administered to the system for the following $16 \mathrm{~h}$ (adaptation period). After that, the microbiota was deprived of any medium for $2 \mathrm{~h}$ (starvation) in order to let it consume the substrates received previously. After this starvation period, the meal of interest was administrated to the microbiota during the following $72 \mathrm{~h}$.

The tested meals or the control SIEM medium were gradually introduced into the system through a feeding syringe. In particular, $60 \mathrm{ml}$ of the SIEM medium was introduced in the system during the $16 \mathrm{~h}$ adaptation period, while $270 \mathrm{ml}$ of the control SIEM or of a certain tested meal were introduced during the following $72 \mathrm{~h}$, at a rate of $0.067 \mathrm{ml} / \mathrm{min}$.

Samples from the lumen and dialysate were collected at the end of the starvation period (time $0 \mathrm{~h}$ ), and 24, 48 and $72 \mathrm{~h}$ after the beginning of the intervention with the meal of interest (time $24 \mathrm{~h}$, time $48 \mathrm{~h}$ and time $72 \mathrm{~h}$, respectively). Samples were analysed for short-chain fatty acids (SCFA) and branched-chain fatty acids (BCFA) production at each time point, while they were analysed for microbiota composition at time $0 \mathrm{~h}$ and time $72 \mathrm{~h}$.

\section{Short-chain and branched-chain fatty acids analyses}

SCFAs (acetate, propionate and $n$-butyrate) and BCFAs (iso-butyrate and iso-valerate) were analysed on a TRACE GC Ultra Gas Chromatograph system coupled with a FID detector (Interscience, Breda, the Netherlands), as described in detail by Ladirat et al. (2014). Briefly, $50 \mathrm{ml}$ of samples or standards were mixed with $50 \mathrm{ml}$ of $0.15 \mathrm{M}$ oxalic acid; after $30 \mathrm{~min}, 150 \mathrm{ml}$ water was added and $1 \mathrm{ml}$ of the sample was analysed.

\section{Microbiota analysis}

Genomic DNA isolation from TIM-2 samples was done using standard molecular biology kits from ZYMO Research provided by BaseClear (Leiden, the Netherlands). PCR amplification of the 16S rRNA gene (V3-V4 region), barcoding and library preparation were performed by BaseClear. Short paired-end sequence reads were generated using the Illumina MiSeq system (San Diego, CA, USA) and converted into FASTQ files using the BCL2FASTQ pipeline version 1.8.3. Quality trimming was applied based on Phred quality scores. Subsequently sequences were analysed using the QIIME-pipeline version 1.9.1 (Caporaso et al., 2010).

\section{Data analyses and presentation}

All experiments were performed in duplicate $(\mathrm{n}=2)$ and results are presented as average of duplicates. Due to the number of experimental replicates, no statistical analyses were performed, except for the comparison of microbiota composition among $\mathrm{H}, \mathrm{P}$ and $\mathrm{D}$ samples at time $0 \mathrm{~h}$. In this case, a Student's t-test was carried out.

Regarding SCFA and BCFA production, concentration of metabolites at the start of the test period (time $0 \mathrm{~h}$ ) was set to zero. In addition to total amounts produced, for each of the tested meals, SCFA and BCFA amounts obtained after the intervention with the control meal (SIEM) were subtracted from the amounts produced after the treatment with the meal of interest, therefore reported amounts are normalised and represent the net effect of each treatment.

Regarding microbiota composition, for comparative analyses of the samples at the genus and species levels, thresholds of 1 and $0.1 \%$ with respect to the total composition were used, respectively; thereafter average values among replicates were calculated. Modulation was calculated and expressed as the difference between the abundances of a given microbial group, at time $72 \mathrm{~h}$ and time $0 \mathrm{~h}(\Delta 72 \mathrm{~h}-0 \mathrm{~h})$, further normalised for the difference $(\Delta 72 \mathrm{~h}-0 \mathrm{~h})$ of the control meal; in particular, $\Delta 72 \mathrm{~h}-0 \mathrm{~h}$ of the control meal was subtracted from $\Delta 72 \mathrm{~h}-0 \mathrm{~h}$ of the treatment of interest.

Correlations between microbial taxa and dietary interventions were evaluated using Kruskal-Wallis analysis, while correlations between taxa and metabolite concentrations were done using Spearman correlations. Both were corrected for multiple corrections using the false discovery rate (FDR) correction. A rather strict FDRcorrected $P$-value ( $q$-value) was chosen, where $q<0.05$ was considered significant. Spearman correlations are shown on the basis of the rho-correlation factor. Only those rhofactors are shown for $q$-values $<0.05$. 


\section{Results}

\section{SCFA/BCFA production}

Total SCFA (acetate, propionate plus butyrate) production at the end (time $72 \mathrm{~h}$ ) of each intervention in TIM-2 model inoculated with the three microbiota, representing healthy $(\mathrm{H})$, pre-diabetic $(\mathrm{P})$, and diabetic $(\mathrm{D})$ state is showed in Figure 1. The individual amounts of acetate, propionate and butyrate for each treatment are reported in Supplementary Figure S1, while data normalised with respect to the SIEM medium (control meal) are presented in Figure 2. The production of SCFAs over time during the $72 \mathrm{~h}$ test period in TIM-2 runs is shown in Supplementary Figure S2.

At the end of the interventions, the highest production of total SCFAs was observed after the treatments with the WGP and the WGP $+\mathrm{BC} 30$ in the microbiota from the three groups of children (H, P, and D) (Figure 1, Supplementary Figure S2). Acetate and butyrate constituted the main products of all fermentations, while propionate was the lowest in relative ratio after any dietary treatment, in the three microbiotas (Supplementary Figure S1); moreover, propionate always was decreased after treatments, as compared to the control (Figure 2).

The production of butyrate was maximised with a concomitant reduction of acetate after the treatment with BC30+ $\beta$-glucans, the dWGP and the dINNP (Figure 2, Supplementary Figure S1), which presented the highest butyrate/acetate ratio, in each of the three microbiota. Moreover, in the D microbiota, also the treatment with

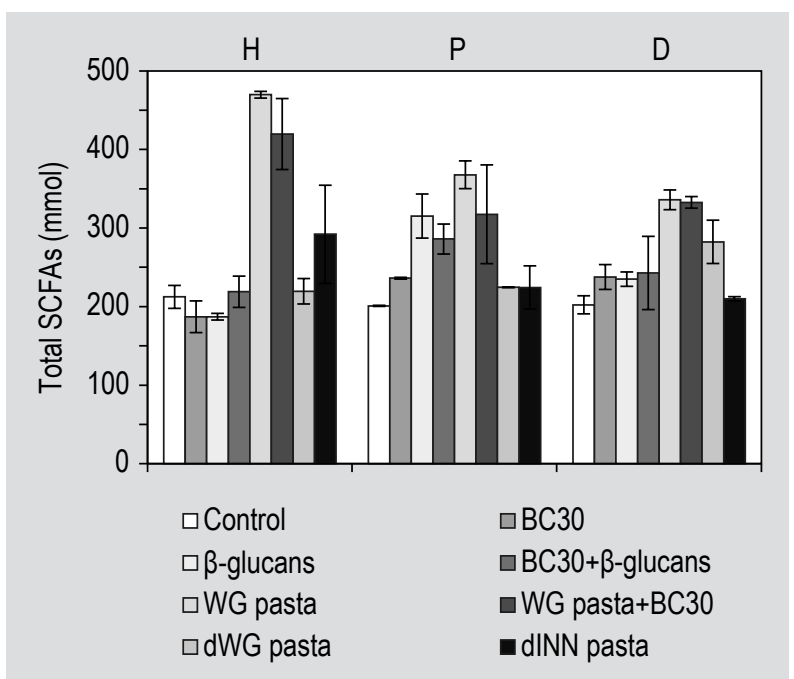

Figure 1. Production of total short chain fatty acid (SCFAs) in TIM-2 after $72 \mathrm{~h}$ of dietary interventions, related to the microbiota from healthy $(\mathrm{H})$, pre-diabetic $(\mathrm{P})$ and diabetic (D) children. Values are expressed as mean + range. Dietary interventions consisted of: the SIEM medium (control); Bacillus coagulans GBI-30, 6086 (BC30); $\beta$-glucans; a combination of $B C 30$ and $\beta$-glucans (BC30+ $\beta$-glucans); a whole-grain pasta, $27 \mathrm{~g} /$ day (WG pasta); a whole-grain pasta with BC30, $27 \mathrm{~g} /$ day (WG pasta+BC30); a whole-grain pasta, $13.5 \mathrm{~g} /$ day (dWG pasta); a whole-grain pasta containing $\mathrm{BC} 30$ and $\beta$-glucans, $13.5 \mathrm{~g} /$ day (dINN pasta).
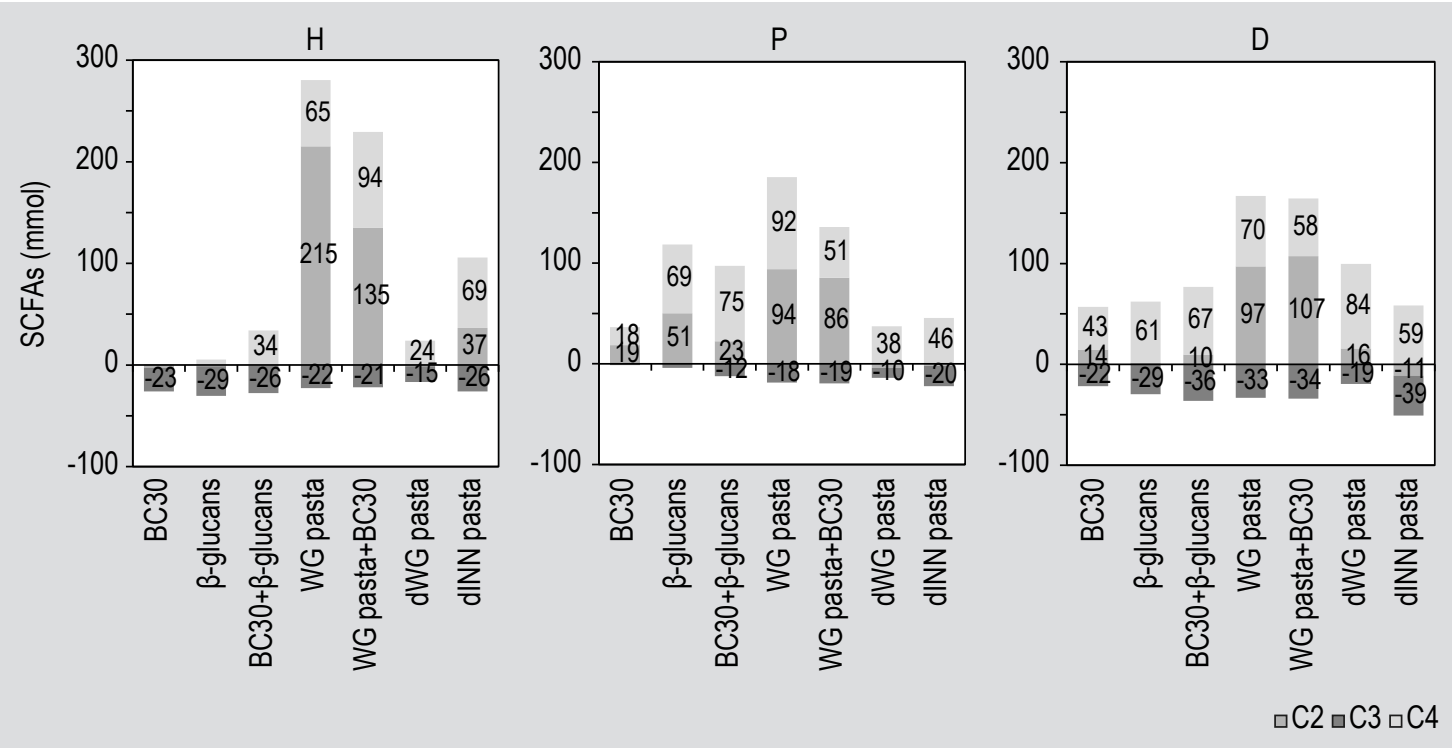

Figure 2. Production of acetate (C2), propionate (C3) and butyrate (C4) in TIM-2 after $72 \mathrm{~h}$ of dietary interventions related to the microbiota from healthy $(H)$, pre-diabetic $(P)$ and diabetic $(D)$ children. Dietary interventions as in Figure 1. Results are normalised for data obtained from intervention with the SIEM medium (control). Labels referred to values included in the range $-5 \leq x \leq 5$ (mmol) are not reported on the graphs. 
$\beta$-glucans caused such a similar preferential butyrate production.

On the contrary, acetate was the main metabolite obtained following the treatments with the WGP and WGP+BC30 (i.e. the meals with the highest dose of starch), in $\mathrm{H}$ and D microbiota, and after intervention with the WGP with BC30, in P microbiota (Figure 2, Supplementary Figure S1).

Analysis of BCFAs was also carried out, setting to zero the amounts of iso-butyrate and iso-valerate at the start of the intervention period (time $0 \mathrm{~h}$ ). The production of BCFAs was generally higher in the $\mathrm{H}$ microbiota, and lower in the P and D microbiota (Supplementary Figure S3). Highest BCFA production ( $>10 \mathrm{mmol}$ ) was obtained in the three microbiota after administration of the control meal. Moreover, in $\mathrm{H}$ and $\mathrm{P}$ microbiota, a high BCFA production (about 11-12 mmol) was obtained after administration of the probiotic strain only.

Considering the different impact of diverse dietary interventions on the production of SCFAs and BCFAs, microbiota composition was investigated at the baseline and after each intervention to define the microbial background responsible for the observed functional effects.

\section{Microbiota composition}

$16 S$ rDNA amplicon sequencing analyses at the beginning of the in vitro interventions

A first investigation was performed on the microbiota from the three groups of children at the beginning of the in vitro experiments (time $0 \mathrm{~h}$ ), i.e. after the $16 \mathrm{~h}$ adaptation period and the $2 \mathrm{~h}$ starvation period in the TIM- 2 model. Analyses were conducted at the genus and species level (Supplementary Table S1 and S2), and expressed, for each of the three groups, as average of the profiles obtained in the replicates (Figure 3).

Results at this time point showed that the three microbiotas exhibited differences in the composition, in terms of presence and/or abundance of different genera. Bacteroides and Bifidobacterium were present in the $\mathrm{H}$ microbiota at low amounts (approximately 8.6 and 19.7\% of the total microbiota, respectively), and they were higher in P microbiota (12.4 and 35.1\%) and even higher in the D microbiota (20.1 and $42.4 \%$ ). On the contrary, the genus Gemmiger was present in high proportion in the $\mathrm{H}$ microbiota (28.1\%) and in low proportion in the D microbiota (3.7\%). Also Faecalibacterium was found at higher levels in the $\mathrm{H}$ microbiota (17.8\%) and it was lower in P (10.8\%) and D microbiota (4.6\%). Differences in average abundances of the genus Collinsella were also observed (10.2\% in the H microbiota, $17.8 \%$ in the P microbiota, $7.5 \%$ in the D microbiota). Moreover, Ruminococcus was

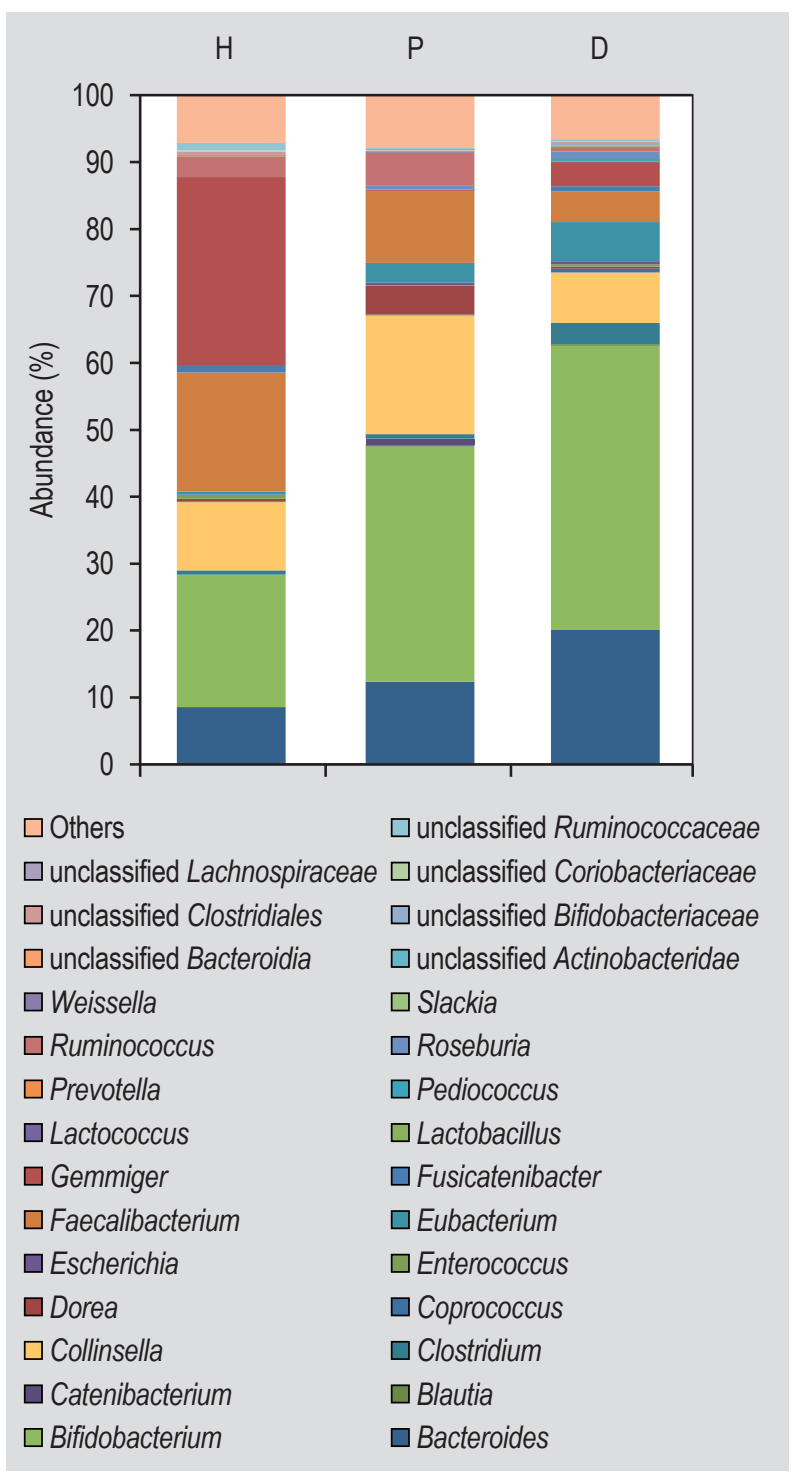

Figure 3. Average composition in percentage at the genus level of the microbiota from healthy $(H ; n=16)$, pre-diabetic $(P ; n=15)$ and diabetic $(D ; n=16)$ children at the beginning of the in vitro intervention (time $0 \mathrm{~h}$ ) in TIM-2.

present in $\mathrm{H}$ and $\mathrm{P}$ microbiota (3.1\% and $4.9 \%$, respectively), Eubacterium in P and D microbiota (2.9\% and 5.9\%), Dorea in P microbiota (4.3\%), and Clostridium (3.2\%) in D microbiota.

At the species level, different microorganisms appeared to be statistically associated with the diverse microbiota from the three children groups (Supplementary Table S3). Among those, Bifidobacterium adolescentis appeared strongly characteristic of both the $P$ and D microbiota, and Gemmiger formicilis of the $\mathrm{H}$ microbiota. 
$16 S$ rDNA amplicon sequencing analyses after the $72 h$ in vitro interventions

Modulations of single genera were observed after the in vitro interventions (Figure 4 and 5) to obtain information on microbial setting related to the observed SCFA production.

The most remarkable result was a dramatic increase in Bifidobacterium in the microbiotas from the three groups of children $(\mathrm{H}, \mathrm{P}$, and $\mathrm{D})$ with the interventions leading to the highest production of total SCFAs (WGP and WGP+BC30) (Figure 5A and 5B, respectively). In particular,

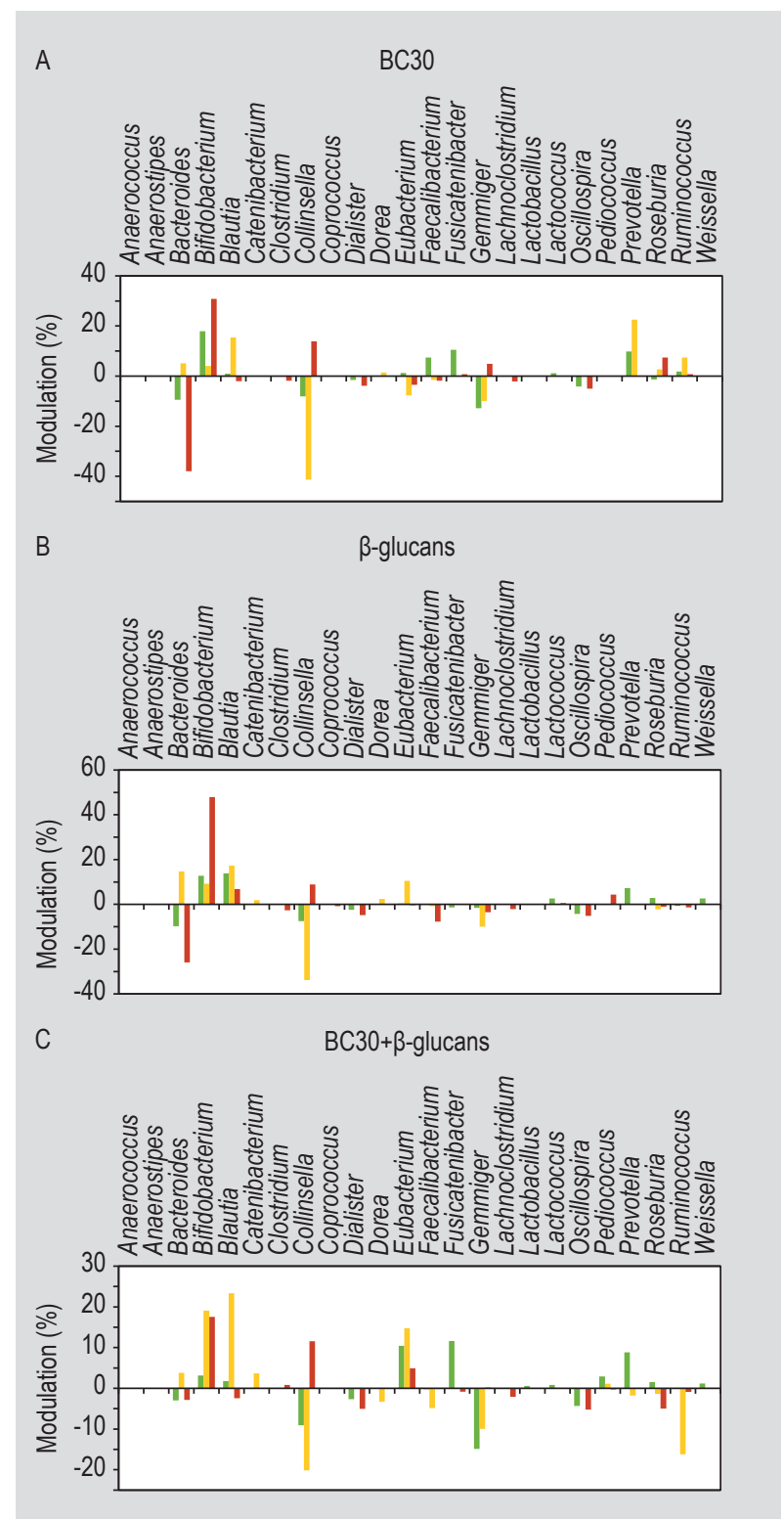

Figure 4. Modulations of bacterial genera in percentage in TIM-2 after $72 \mathrm{~h}$ of interventions with the functional ingredients (i.e. (A) the probiotic strain $\mathrm{BC} 30$; (B) the $\beta$-glucans; and (C) $B C 30+\beta$-glucans) in the microbiota from healthy $(H$, in green), pre-diabetic $(P$, in yellow) and diabetic $(D$, in red) children.
Bifidobacterium modulations of $68.5,51.3$ and $90.7 \%$ in the $\mathrm{H}, \mathrm{P}$ and D microbiotas, respectively, were obtained after treatment with the WGP, while increases of 60.6, 48.8 and $65.0 \%$, respectively, were determined on the WGP+BC30.

After that, microbial components related to conditions in which butyrate or acetate production was maximised with respect to the other metabolite were investigated (Figure 2 ). An increase in butyrate producers was observed in most cases in the treatments $B C 30+\beta$-glucans, dWGP, and dINNP, and the administration of $\beta$-glucans only for the $D$ microbiota, i.e. the interventions determining the highest production of butyrate with a parallel low production of acetate.

In detail, in the $\mathrm{H}$ microbiota, high butyrate levels following $\mathrm{BC} 30+\beta$-glucans administration could be related to an increase in Eubacterium (10.4\%) and Roseburia (1.6\%) (Figure 4C), while increases observed following administration of dINNP could be supported by the increase in Eubacterium (5.6\%) and Faecalibacterium (9.5\%) (Figure $5 \mathrm{D})$. No increases in known butyrate producers were revealed following the intervention with dWGP (Figure 5C).

In the P microbiota, two butyrate-producing genera were increased following $\mathrm{BC} 30+\beta$-glucans administration, i.e. Catenibacter (3.7\%) and Eubacterium (14.8\%) (Figure 4C). After treatment with the dINNP, Faecalibacterium increased (2.7\%) (Figure 5D), while dWGP caused primarily an increase in Eubacterium (2.0\%) and a small increase in Faecalibacterium (0.7\%) (Figure 5C).

Finally, in the D microbiota, predominance of butyrate production following the intervention with the combination of BC30+ $\beta$-glucans matched with increases in Clostridium (0.8\%), Eubacterium (4.9\%) and Gemmiger (0.2\%) (Figure 4C); with the dINNP an increase in Clostridium (5.5\%) was registered (Figure 5D); Gemmiger (7.3\%) increased after treatment with the dWGP (Figure 5C). In the D microbiota, also administration of $\beta$-glucans caused a high butyrate level, although, in this condition, no increases in known butyrate producers were revealed (Figure 4B).

Concerning high production of acetate, observed following intervention with the WGP+BC30 in $\mathrm{H}, \mathrm{P}, \mathrm{D}$ microbiota (Figure 2), and with WGP in the $\mathrm{H}$ and D microbiota (Figure 2), a parallel marked increase in Bifidobacterium was shown (Figure 5B and 5A, respectively). In P microbiota after treatment with WGP, condition in which acetate and butyrate were produced at a similar amount (Figure 2), an increase in Eubacterium was detected (5.0\%) (Figure $5 \mathrm{~A}$ ) with the species Eubacterium rectale (Supplementary Table S2).

Interestingly, the only treatment that favoured the production of propionate was the control meal, and in 
A

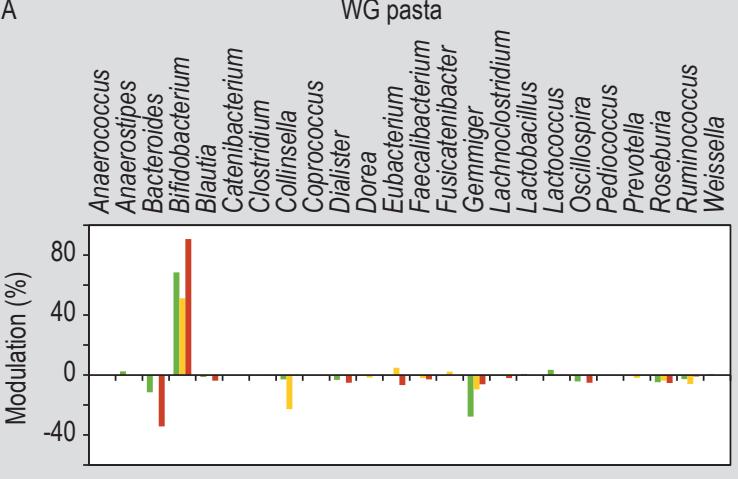

C
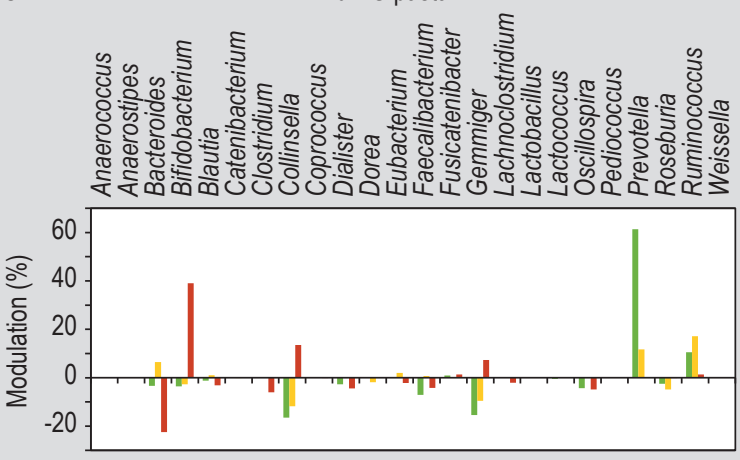

B

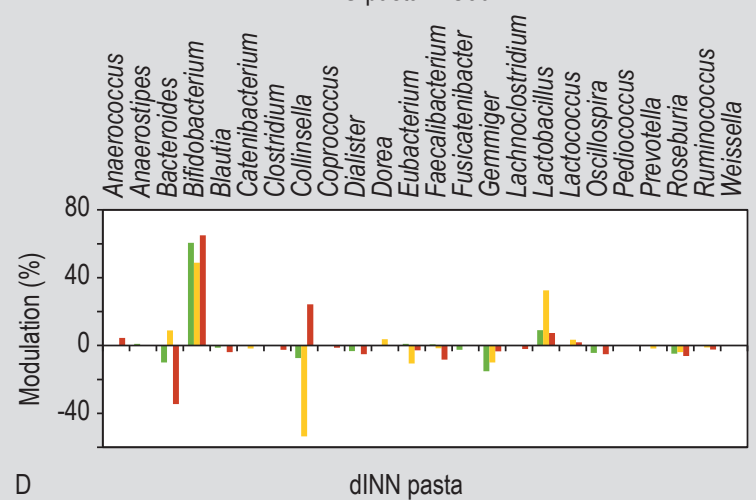

D

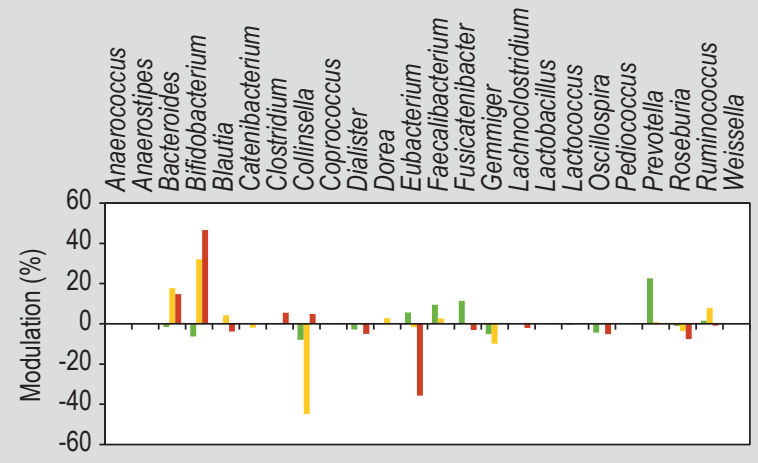

Figure 5. Modulations of bacterial genera in percentage in TIM-2 after $72 \mathrm{~h}$ of interventions with the different pastas (i.e. (A) the whole-grain pasta, $27 \mathrm{~g} /$ day (WG pasta); (B) the whole-grain pasta with BC30, $27 \mathrm{~g} /$ day (WG pasta+BC30; (C) the whole-grain pasta, $13.5 \mathrm{~g} /$ day (dWG pasta); (D) the whole-grain pasta containing BC30 and $\beta$-glucans (dINN pasta), $13.5 \mathrm{~g} /$ day) in the microbiota from healthy $(H$, in green), pre-diabetic $(P$, in yellow) and diabetic $(D$, in red) children.

this condition high levels in Bacteroides population were observed in $\mathrm{H}$ and $\mathrm{D}$ microbiota. Here, this genus remained stable during treatment with this meal (about 13.0 and $12.9 \%$ at time $0 \mathrm{~h}$ and time $72 \mathrm{~h}$ in the $\mathrm{H}$ microbiota, and about $25.6 \%$ at time $0 \mathrm{~h}$ and $32.0 \%$ at time $72 \mathrm{~h}$ in the D microbiota) (Supplementary Table S1).

To complete the analyses, overall modulations of microbial taxa following each of the tested dietary interventions were explored. In most cases, a specific treatment led to different responses in the microbiota of the three groups, i.e. different patterns of microbial genera were increased in one specific microbiota, but not in another (Figure 4 and 5; Supplementary Figure S4). However, some specific interventions led to variations in microbial groups that were shared by the $\mathrm{H}, \mathrm{P}$ and $\mathrm{D}$ microbiotas.

In more detail, B. coagulans $\mathrm{BC} 30$ appeared to have a bifidogenic effect, either in $\mathrm{H}(17.9 \%), \mathrm{P}(4.0 \%)$ or $\mathrm{D}$ microbiota (30.8\%) (Figure 4A). $\beta$-glucans, also, had a marked effect on Bifidobacterium, on the $\mathrm{H}, \mathrm{P}$ and D microbiota (12.7\%, 9.2\%, and 48.0\%, respectively) (Figure 4B). Moreover, a shared effect of the three microbiotas following $\beta$-glucans administration was related to increases in Blautia (13.9\%, 17.3\%, 6.8\%, respectively) (Figure 4B).
When $\mathrm{BC} 30$ and $\beta$-glucans were administered together, increases in Bifidobacterium were observed for the three microbiotas (3.1, 19.1 and $17.6 \%$, respectively), together with increases in Eubacterium (10.4, 14.8 and 4.9\%, respectively) (Figure 4C). When considering the pasta formulations, WGP and WGP+BC30 led to a marked increase of Bifidobacterium as reported above (Figure 5A and 5B). Also the genus Lactobacillus increased after the nutritional treatment WGP+BC30 in the three microbiota (9.0, 32.6 and 7.4\%, respectively) (Figure 5B).

The dWGP had an effect on Ruminococcus in the three microbiotas (10.5, 17.1 and 1.4\%) (Figure 5C) due to the increase of the species Ruminococcus bromii (Supplementary Table S2). Remarkably, no modulations shared in the three microbiotas were observed following administration of dINNP (Figure 5D). Considering the massive increase in the genus Bifidobacterium following administration of WGP and WGP+BC30, the composition in species was analysed in detail at the beginning (time $0 \mathrm{~h}$ ) and at the end (time $72 \mathrm{~h}$ ) of these dietary treatments (Figure 6). Four species were mostly involved in the pronounced growth of this microbial group, i.e. B. adolescentis, Bifidobacterium animalis, Bifidobacterium pseudocatenulatum, and Bifidobacterium pseudolongum (Figure 6, Supplementary Table S2). 


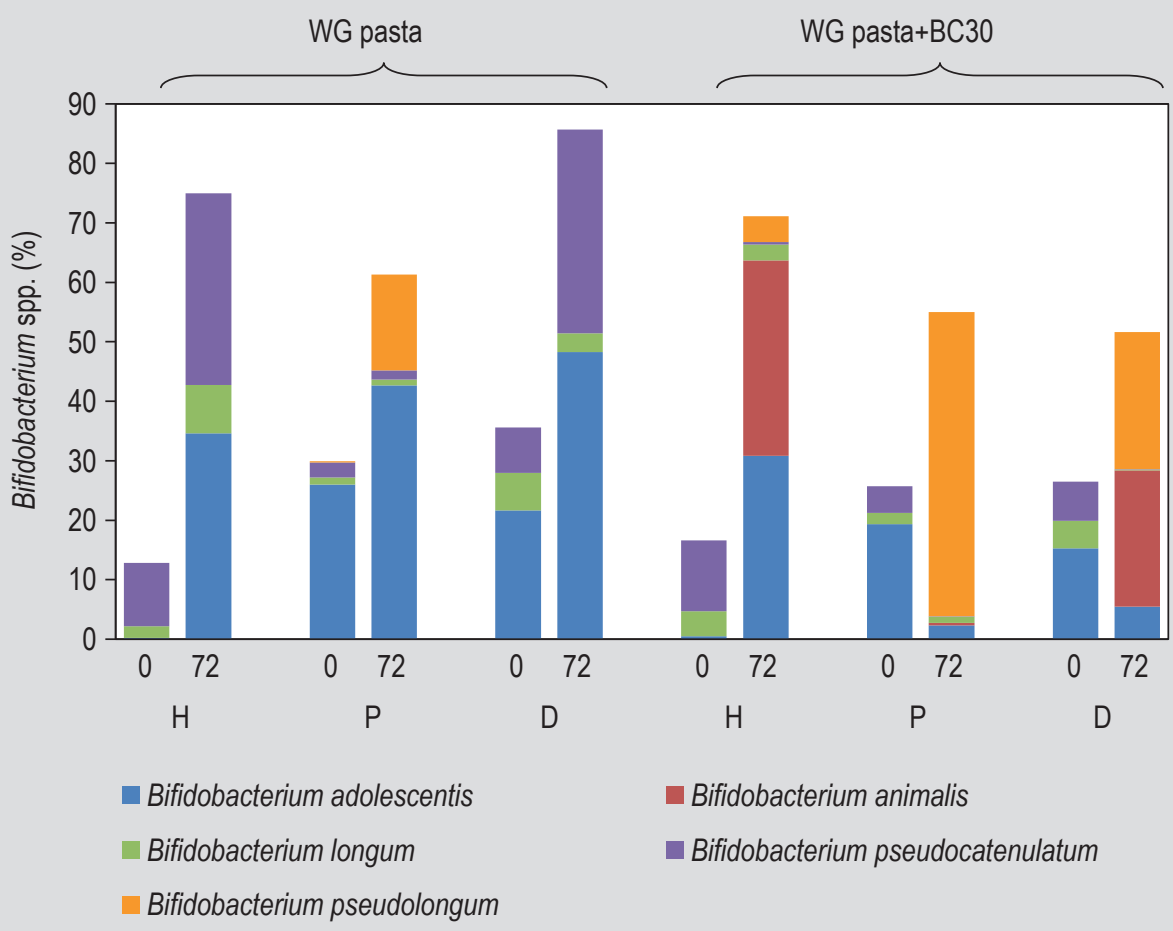

Figure 6. Bifidobacterium spp. abundance in percentage at the beginning (time $0 \mathrm{~h}$ ) and at the end (time $72 \mathrm{~h}$ ) of the intervention in TIM-2 with the whole-grain pasta (WG pasta) and the whole-grain pasta with BC30 (WG pasta+BC30), in the microbiota from healthy $(\mathrm{H})$, pre-diabetic $(\mathrm{P})$ and diabetic $(\mathrm{D})$ children.

Correlation analysis was done between microbial taxa and the active ingredients (BC30, $\beta$-glucans and pasta). Multiple corrections were applied using false discovery rate (FDR). The $q$-values (FDR-corrected $P$-values) for the Kruskal-Wallis correlations are shown in Table S4 and have been determined for the individual microbiotas as well as all microbiotas combined. In all cases, the intervention with $\mathrm{BC} 30$ correlates with an increase in the genus Bacillus, although for the diabetic microbiota this was a trend $(q=0.065)$. For this microbiota there were no other correlations. For the prediabetic microbiota, this correlation between $\mathrm{BC} 30$ and Bacillus was the only correlation, whereas with the healthy microbiota, many more correlations between tax $a$ and BC30 feeding occurred. Addition of $\beta$-glucans correlated to the modulation of a number of taxa only in the healthy microbiota, and in the combined dataset of all three microbiotas together. Addition of pasta correlated with the modulation of a number of taxa in the prediabetic microbiota, but more so in the healthy microbiota, although some taxa overlapped between the two microbiotas (Supplementary Table S4).

Using Spearman correlation microbial taxa were also correlated to production of the microbial metabolites. This analysis was carried out within a particular microbiota (H, P, D and combined; Figure S5), as well as within the individual interventions (BC30; $\beta$-glucans; a combination of $\mathrm{BC} 30$ and $\beta$-glucans; the whole-grain pasta at $27 \mathrm{~g} /$ day
(WG pasta); the whole-grain pasta at $13.5 \mathrm{~g} / \mathrm{day}$ (dWG pasta); the whole-grain pasta with $B C 30$ (WG pasta $+B C 30$ ); and the whole-grain pasta containing $\mathrm{BC} 30$ and $\beta$-glucans (dINN pasta); Supplementary Figure S6). Comparison within microbiotas revealed numerous positive and negative correlations between taxa and metabolites (Supplementary Figure S5). Iso-valerate did not correlate to specific taxa in the individual microbiotas, and only to two taxa in the combined dataset. Acetate only correlated to taxa in the diabetic microbiota (and in the combined dataset), while propionate only correlated in the healthy and diabetic microbiotas (and in the combined dataset). Butyrate and iso-butyrate correlated to taxa in all datasets. Correlations in the individual dataset in general were stronger than when the three datasets were combined, as evidenced by the colour intensity of the correlations in Supplementary Figure S5.

Supplementary Figure S6 shows the correlations between microbial taxa and metabolite production after the 7 different interventions (with the three microbiota datasets combined). Addition of $\mathrm{BC} 30, \beta$-glucans or the combination of both primarily led to positive taxa-metabolite correlations, whereas pasta primarily led to negative taxa-metabolite correlations. The modulation of both the composition and the activity of the microbiota was clearly substrate specific. When substrates were combined this did not lead to clear synergistic effects, as for instance observed 
by the combination of $\mathrm{BC} 30$ and $\beta$-glucans, which showed less correlations than when they were applied individually. And the 4 taxa that were correlated with metabolites upon feeding both bioactive components together showed differences compared to the individual substrates, with e.g. Anaerococcus being positively correlated with butyrate after feeding $\beta$-glucans, but $\beta$-glucans in combination with $\mathrm{BC} 30$ leading to a positive correlation with propionate, whereas upon feeding with $\mathrm{BC} 30$ alone, Anaerococcus did not correlate to either of these metabolites (Supplementary Figure S6).

\section{Discussion}

Functional foods represent a very interesting approach to the improvement of an individual's well-being via the manipulation of gut microbiota (Bosscher et al., 2009). For investigating the impact of a dietary intervention on gut microbiota, human trials represent the gold standard. However, clinical trials are expensive and difficult to control, mainly because participants often differ in their dietary behaviour and lifestyle (Graf et al., 2015). Moreover, functional redundancy of gut microbiota members hinders the recognition of specific mechanisms of actions of functional foods/ingredients (Rowland et al., 2017). Therefore, outcomes of specific dietary interventions are difficult to predict.

In this context, in vitro models could be an extraordinary tool to collect preliminary specific information about the effects of new functional foods and/or ingredients, prior to personalised intervention in humana, since they allow to obtain detailed information on specific effects of each tested treatment on the gut microbiota function (in terms of produced SCFAs) as well as microbiota composition in a quick, easy and cost-effective way (Venema and Van den Abbeele, 2013; Williams et al., 2015).

In the present study, the TIM-2 in vitro model of the proximal colon (Minekus et al., 1999) was inoculated with pools of faecal material derived from children with different susceptibility to T1D (H, P and D), and different dietary treatments were tested. Outcomes of the treatments were evaluated in terms of SCFA production and changes in microbiota composition, focusing on the increase in beneficial/health promoting bacterial groups, e.g. Bifidobacterium species, and producers of beneficial metabolites, such as butyrate, e.g. Faecalibacterium prausnitzii. Results of the experiments showed that treatments characterised by the highest dose of starch (WGP and WGP+BC30) led to the highest amounts of SCFAs in the three microbiotas. This evidence was consistent with literature, since starch is considered to provide the largest proportion of energy at the colon level (Duncan et al., 2003).
BCFAs, that include primarily iso-butyrate and iso-valerate, are toxic metabolites that are derived from proteolytic fermentation, and their amount in faecal samples increase following a high protein diet (Maathuis et al., 2009). High BCFA levels were obtained in the three microbiota following treatment with the control meal, and in $\mathrm{H}$ and $\mathrm{P}$ microbiota after intervention with $\mathrm{BC} 30$; those effects could be related to the lower amount of fibres in these meals, compared with most of the other meals, which is thought to have favoured proteolytic fermentation; in other interventions, higher amount of fermentable carbohydrates reduced utilisation of proteins.

Correlating results of SCFA production and microbial composition, the observed increases in metabolite production were almost always consistent with increases in bacterial taxa with related metabolism, even though different known butyrate producers increased in the different samples, i.e. Catenibacter, Clostridium, Eubacterium, Faecalibacterium, Gemmiger, and Roseburia, confirming functional redundancy of microbiota (Louis et al., 2010). Also, high acetate production and proportion with respect to butyrate observed after treatments with the highest amount of starch was consistent with the marked increase in Bifidobacterium populations. In fact, Bifidobacterium spp. mainly produce acetate and lactate through carbohydrate degradation metabolism (De Vuyst et al., 2014). Only in one case, i.e. the treatment with WGP in the P microbiota, butyrate equalled acetate production and this was related with a marked increase in E. rectale, one of the most abundant butyrate producers in the human gut (Louis et al., 2010). Finally, the presence of Bacteroides populations at a high amount following treatment with the control meal could explain high levels of propionate observed, consistently with Bacteroides metabolism (Macy et al., 1978).

It has to be underlined that modulations of specific bacterial groups were mostly microbiota-dependent, i.e. intervention with the same treatment produced different responses in the three microbiotas in term of increase or decrease of certain microbial taxa. This could be due to the differences in composition observed in the three microbiota at the baseline of the experiments, that may have led to alternative cross-feeding. However, some of the nutritional interventions always led to modulations of specific microbial groups regardless of the initial diversity of the three microbiotas as consortia. Those modulations are the most informative to devise a mechanism of action for the studied dietary interventions which could directly affect microbial taxa. In particular, the increase in Blautia spp. observed after administration of $\beta$-glucans was consistent with a previous study in humana that showed an increase in this genus following ingestion of whole-grain barley flakes containing $\beta$-glucans (Martínez et al., 2013). Also, the increase in Eubacterium spp., and especially in 
E. rectale, could be linked to the administration of $\mathrm{BC} 30$ and $\beta$-glucans, in agreement with the previously reported observation of an increase in $E$. rectale after combined administration of the probiotic strain $\mathrm{BC} 30$ and a prebiotic (i.e. FOS or GOS) (Nyangale et al., 2014). The dWGP, which presented a lower dose of starch with respect to the WGP, caused an increase in $R$. bromii, consistently with previous findings that indicated $R$. bromii as a key species in the degradation of resistant starch in the human colon (Kovatcheva-Datchary et al., 2009; Walker et al., 2011; Ze et al., 2012). Increases in Ruminococcus genus or R. bromii were not observed after the administration of higher doses of starch, i.e. WGP and WGP+BC30, probably because of the massive increase in Bifidobacterium spp.

Intervention with the two functional ingredients, $B$. coagulans $\mathrm{BC} 30$ and $\beta$-glucans, administered separately or in combination, always showed an increase in Bifidobacterium. A bifidogenic effect was already known for $\beta$-glucans, in vitro (Hughes et al., 2008; Kedia et al., 2009) and in humana (Arena et al., 2014; Mårtensson et al., 2005; Mitsou et al., 2010), but this evidence was not previously reported for BC30 (Honda et al., 2011; Nyangale et al., 2015). A Bacillus subtilis strain (C-3102) was previously shown to also increase Bifidobacterium in vitro in the same model (Hatanaka et al., 2012). Also, a marked growth in Bifidobacterium spp. was observed after administration of the WGP and the WGP $+\mathrm{BC} 30$ (i.e. treatment with the highest doses of starch), where Bifidobacterium represented the dominant genus ( $>50 \%$ of the total population) at the end of the in vitro interventions. It has to be considered that such a high increase may be less pronounced in vivo, due to the fact that humans would have a varied diet and thus the bifidogenic effect observed in TIM-2 of a substrate that consisted of nothing but these meals could be exaggerated. Moreover, the enormous increase observed in our study could be linked to the fact that the investigated pastas were whole-grain products, and it has been shown that wholegrain cereal products from wheat (Costabile et al., 2008), or other cereal, e.g. maize (Carvalho-Wells et al., 2010), have a more pronounced bifidogenic effect than that observed with non-whole-grain cereals.

Even if Bifidobacterium spp. is believed to be a beneficial bacterial group (Bosscher et al., 2009), interestingly, in the present study, Bifidobacterium was found to be present in higher abundances in the $\mathrm{P}$ and $\mathrm{D}$ microbiota compared to the $\mathrm{H}$ one. Number of donors $(\mathrm{n}=2)$ for each microbiota represent a small cohort, that makes not possible to draw conclusions among microbiota settings in different states of T1D susceptibility. However, some interesting features were observed, that will worth to further investigate. $B$. adolescentis was among the species found at high level in $\mathrm{P}$ and $\mathrm{D}$ microbiota at the beginning of the experiments. B. adolescentis has been previously reported as associated to certain disease conditions, such as allergies, IBS, and asthma (Arboleya et al., 2016; Sánchez et al., 2010). Administration of WGP led to an increase in B. adolescentis, in each of the three microbiotas, consistent with previous studies dealing with consumption of starch (Martínez et al., 2010; Venkataraman et al., 2016). On the contrary, interestingly, in the P and D microbiota, $B$. adolescentis decreased after the intervention with WGP+BC30. Thus, considering B. adolescentis as a hypothetical marker of a pre-pathological/pathological condition, a treatment with WGP $+\mathrm{BC} 30$ that could reduce this microbial species would be potentially advisable. Also, the increase in $B$. animalis appears related to the presence of the probiotic strain, acting in a synergistic way with WGP: in fact, this species increased after intervention with WGP+BC30 (particularly in $\mathrm{H}$ and $\mathrm{D}$ microbiota), but it was not present in the three microbiota after treatment with WGP. In literature, growth of $B$. animalis has been reported after administration of a probiotic mixture (Lactobacillus and Bifidobacterium strains) together with a prebiotic, i.e. inulin, in rats presenting colitis (Schultz et al., 2004).

Further, the increase in Lactobacillus spp. in the three microbiotas following administration of WGP + BC30 represented a positive effect in term of increased healthpromoting organisms. Also in this case, the effect was probably due to the simultaneous presence of the probiotic strain and the starch contained in the pasta. Moreover, the increase in Lactobacillus species could have been mediated by the formerly discussed increase in B. animalis. In fact, it has been reported that $B$. animalis could promote the growth of Lactobacillus species in in vitro fermentations, through production of exopolysaccharides (Salazar et al., 2009).

In terms of metabolite production, an increase in SCFA production with specific reference to butyrate could represent the most desirable outcome: in fact, butyrate is considered a beneficial metabolite that contributes to colon health, representing the energy source for the colonic epithelial cells, and contributing to gut integrity (Conlon and Bird 2015; Ríos-Covián et al., 2016). This also applies in the case of T1D (Brown et al., 2011). Thus, in the present study, results obtained suggest a positive effect of wholegrain tested products.

Results obtained in the present study suggest that despite microbiota-dependent responses to a dietary intervention, specific diet-microbial taxa associations and microbial taxa-metabolite production exist, indicating that each ingredient was modulating the microbiota in a different manner, and thus providing information on possible mechanisms of action of food ingredients and their combinations in the gut. Also, our results suggest that the combination of the probiotic and prebiotic ingredients, as well as the innovative dINNP and dWGP, determined the production of high amounts of butyrate, which can 
be considered a positive effect, also in T1D context, and therefore open a new perspective for future trials in humana.

From a methodological viewpoint, TIM-2 model appeared to be an effective tool to obtain robust insights in the impact of different dietary treatments on standardised microbiota highlighting specific mechanisms of action of the different components tested.

\section{Supplementary material}

Supplementary material can be found online at https://doi. org/10.3920/BM2018.0088.

Table S1. Abundance (\%) of bacterial genera in TIM-2 at time $0 \mathrm{~h}$ and after $72 \mathrm{~h}$ of dietary interventions related to the microbiota from healthy, pre-diabetic and diabetic children.

Table S2. Abundance (\%) of bacterial species in TIM-2 at time $0 \mathrm{~h}$ and after $72 \mathrm{~h}$ of dietary interventions related to the microbiota from healthy, pre-diabetic and diabetic children.

Table S3. Abundance (\%) of bacterial species in TIM-2 at time $0 \mathrm{~h}$, after the $16 \mathrm{~h}$-adaptation period in the system, related to the microbiota from healthy, pre-diabetic and diabetic children.

Table S4. Kruskal-Wallis correlations between microbial tax $a$ and bioactive ingredients.

Figure S1. Production of acetate, propionate and butyrate in TIM-2 after $72 \mathrm{~h}$ of dietary interventions related to the microbiota from healthy, pre-diabetic and diabetic children, expressed as absolute amounts or relative proportions of total SCFA production.

Figure S2. Production of total short chain fatty acids, acetate, propionate, and butyrate at $0,24,48$ and $72 \mathrm{~h}$ of TIM-2 dietary interventions related to the microbiota from healthy, pre-diabetic and diabetic children.

Figure S3. Production of branched chain fatty acid (isobutyrate and iso-valerate) in TIM-2 after $72 \mathrm{~h}$ of dietary interventions related to the microbiota from healthy, prediabetic and diabetic children.

Figure S4. Modulations of bacterial genera and production of acetate, propionate and butyrate in TIM- 2 after $72 \mathrm{~h}$ of dietary interventions, related to the microbiota from healthy, pre-diabetic and diabetic children.

Figure S5. Correlations of bacterial taxa with production of microbial metabolites in TIM-2 after dietary interventions, related to the microbiota from healthy, pre-diabetic and diabetic children, or all microbiota datasets combined.
Figure S6. Correlations of bacterial taxa metabolite production after the individual dietary interventions. Taxa were correlated to metabolite concentrations by Spearman correlation corrected by FDR.

\section{Acknowledgements}

We thank Carlota Bussolo de Souza from Maastricht University for her technical assistance in performing the SCFA/BCFA analyses. Dr Giovanna Contreas from Unit of Pediatric Diabetes and Metabolic Diseases, Regional Center for Pediatric Diabetes, University of Verona, is gratefully acknowledged for her help in the recruitment phase of the project. The authors would like to thank David Keller and Howard Cash (Ganeden, Mayfield Heights, OH, USA) for providing the freeze-dried preparation of B. coagulans GBI-30, 6086.

This work was partially funded by the Italian Ministry for Economic Development [grant number MI01_00138] and has been made possible with the support of the Dutch Province of Limburg with a grant to Maastricht University - campus Venlo, Centre for Healthy Eating and Food Innovation, NUTRIM School of Nutrition and Translational Research in Metabolism. AM was supported by a grant of University of Verona in the framework of Bando Cooperint 2015.

\section{Conflicts of interest}

The authors declare no conflict of interest. The funding sponsors had no role in the design of the study; in the collection, analyses, or interpretation of data; in the writing of the manuscript, and in the decision to publish the results.

\section{References}

Arboleya, S., Watkins, C., Stanton, C. and Ross, R.P., 2016. Gut bifidobacteria populations in human health and aging. Frontiers in Microbiology 7: 1204.

Arena, M.P., Caggianiello, G., Fiocco, D., Russo, P., Torelli, M., Spano, G. and Capozzi, V., 2014. Barley $\beta$-glucans-containing food enhances probiotic performances of beneficial bacteria. International Journal of Molecular Science 15: 3025-3039.

Bibbò, S., Dore, M.P., Pes, G.M., Delitala, G. and Delitala, A.P., 2017. Is there a role for gut microbiota in type 1 diabetes pathogenesis? Annals of Medicine 49: 11-22.

Bosscher, D., Breynaert, A., Pieters, L. and Hermans, N., 2009. Foodbased strategies to modulate the composition of the intestinal microbiota and their associated health effects. Journal of Physiology and Pharmacology 60, Suppl. 6: 5-11. 
Brown, C.T., Davis-Richardson, A.G., Giongo, A., Gano, K.A., Crabb, D.B., Mukherjee, N., Casella, G., Drew, J.C., Ilonen, J., Knip, M., Hyöty, H., Veijola, R., Simell, T., Simell, O., Neu, J., Wasserfall, C.H., Schatz, D., Atkinson, M.A. and Triplett, E.W., 2011. Gut microbiome metagenomics analysis suggests a functional model for the development of autoimmunity for type 1 diabetes. PLoS ONE 6: e25792.

Caporaso, J.G., Kuczynski, J., Stombaugh, J., Bittinger, K., Bushman, F.D., Costello, E.K., Fierer, N., Peña, A.G., Goodrich, J.K., Gordon, J.I, Huttley, G.A., Kelley, S.T., Knights, D., Koenig, J.E., Ley, R.E., Lozupone, C.A., McDonald, D., Muegge, B.D., Pirrung, M., Reeder, J., Sevinsky, J.R., Turnbaugh, P.J., Walters, W.A., Widmann, J., Yatsunenko, T., Zaneveld, J. and Knight, R., 2010. QIIME allows analysis of high-throughput community sequencing data. Nature Methods 7: 335-336.

Carvalho-Wells, A.L., Helmolz, K., Nodet, C., Molzer, C., Leonard, C., McKevith, B., Thielecke, F., Jackson, K.G. and Tuohy, K.M., 2010. Determination of the in vivo prebiotic potential of a maize-based whole grain breakfast cereal: a human feeding study. British Journal of Nutrition 104: 1353-1356.

Cloetens, L., Ulmius, M., Johansson-Persson, A., Akesson, B. and Onning, G., 2012. Role of dietary betaglucans in the prevention of the metabolic syndrome. Nutrition Reviews 70: 444-458.

Conlon, M.A. and Bird, A.R., 2015. The impact of diet and lifestyle on gut microbiota and human health. Nutrients 7: 17-44.

Costabile, A., Klinder, A., Fava, F., Napolitano, A., Fogliano, V., Leonard, C., Gibson, G.R. and Tuohy, K.M., 2008. Whole-grain wheat breakfast cereal has a prebiotic effect on the human gut microbiota: a double-blind, placebo-controlled, crossover study. British Journal of Nutrition 99: 110-120.

De Vuyst, L., Moens, F., Selak, M., Rivière, A. and Leroy, F., 2014. Summer Meeting 2013: growth and physiology of Bifidobacteria. Journal of Applied Microbiology 116: 477-491.

Duncan, S.H., Scott, K.P., Ramsay, A.G., Harmsen, H.J., Welling, G.W., Stewart, C.S. and Flint, H.J., 2003. Effects of alternative dietary substrates on competition between human colonic bacteria in an anaerobic fermentor system. Applied and Environmental Microbiology 69: 1136-1142.

Fares, C., Menga, V., Martina, A., Pellegrini., N, Scazzina, N. and Torriani, S., 2015. Nutritional profile and cooking quality of a new functional pasta naturally enriched in phenolic acids, added with $\beta$-glucan and Bacillus coagulans GBI-30, 6086. Journal of Cereal Sciences 65: 260-266.

Gibson, G.R., Cummings, J.H. and Macfarlane, G.T., 1988. Use of a three-stage continuous culture system to study the effect of mucin on dissimilatory sulfate reduction and methanogenesis by mixed populations of human gut bacteria. Applied and Environmental Microbiology 54: 2750-2755.

Graf, D., Di Cagno, R., Fåk, F., Flint, H.J., Nyman, M., Saarela, M. and Watzl, B., 2015. Contribution of diet to the composition of the human gut microbiota. Microbial Ecology in Health and Disease 26: 26164.

Hatanaka, M., Nakamura, Y., Maathuis, A.J., Venema, K., Murota, I. and Yamamoto, N., 2012. Influence of Bacillus subtilis C-3102 on microbiota in a dynamic in vitro model of the gastrointestinal tract simulating human conditions. Beneficial Microbes 3: 229-236.
Honda, H., Gibson, G.R., Farmer, S., Keller, D. and McCartney, A.L., 2011. Use of a continuous culture fermentation system to investigate the effect of GanedenBC30 (Bacillus coagulans GBI-30, 6086) supplementation on pathogen survival in the human gut microbiota. Anaerobe 17: 36-42.

Hughes, S.A., Shewry, P.R., Gibson, G.R., McCleary, B.V. and Rastall, R.A., 2008. In vitro fermentation of oat and barley derived $\beta$-glucans by human faecal microbiota. FEMS Microbiology Ecology 64: 482-493.

Kedia, G., Vázquez, J.A., Charalampopoulos, D. and Pandiella, S.S., 2009. In vitro fermentation of oat bran obtained by debranning with a mixed culture of human fecal bacteria. Current Microbiology 58: 338-342.

Kovatcheva-Datchary, P., Egert, M., Maathuis, A., Rajilić-Stojanović, M., De Graaf, A.A., Smidt, H., De Vos, W.M. and Venema, K., 2009. Linking phylogenetic identities of bacteria to starch fermentation in an in vitro model of the large intestine by RNA-based stable isotope probing. Environmental Microbiology 11: 914-926.

Ladirat, S.E., Schuren, F.H., Schoterman, M.H., Nauta, A., Gruppen, H. and Schols, H.A., 2014. Impact of galacto-oligosaccharides on the gut microbiota composition and metabolic activity upon antibiotic treatment during in vitro fermentation. FEMS Microbiology Ecology 87: 41-51.

Louis, P., Young, P., Holtrop, G. and Flint, H.J., 2010. Diversity of human colonic butyrate-producing bacteria revealed by analysis of the butyryl-CoA:acetate CoA-transferase gene. Environmental Microbiology 12: 304-314.

Maathuis, A., Hoffman, A., Evans, A., Sanders, L. and Venema, K., 2009. The effect of the undigested fraction of maize products on the activity and composition of the microbiota determined in a dynamic in vitro model of the human proximal large intestine. Journal of the American College of Nutrition 28: 657-666.

Macy, J.M., Ljungdahl, L.G. and Gottschalk, G., 1978. Pathway of succinate and propionate formation in Bacteroides fragilis. Journal Bacteriology 134: 84-91.

Maffeis, C., Martina, A., Corradi, M., Quarella, S., Nori, N., Torriani, S., Plebani, M., Contreas, G. and Felis, G.E., 2016. Association between intestinal permeability and faecal microbiota composition in Italian children with beta cell autoimmunity at risk for type 1 diabetes. Diabetes/Metabolism Research and Reviews 32: 700-709.

Mårtensson, O., Biörklund, M., Lambo, A.M., Dueñas-Chasco, M., Irastorza, A., Holst, O., Norin, E., Welling, G., Öste, R. and Önning, G., 2005. Fermented, ropy, oat-based products reduce cholesterol levels and stimulate the bifidobacteria flora in humans. Nutrition Research 25: 429-442.

Martínez, I., Kim, J., Duffy, P.R., Schlegel, V.L. and Walter, J., 2010. Resistant starches types 2 and 4 have differential effects on the composition of the fecal microbiota in human subjects. PLoS ONE 5: e15046.

Martínez, I., Lattimer, J.M., Hubach, K.L., Case, J.A., Yang, J., Weber, C.G., Louk, J.A., Rose, D.J, Kyureghian, G., Peterson, D.A., Haub, M.D. and Walter, J., 2013. Gut microbiome composition is linked to whole grain-induced immunological improvements. ISME Journal 7: 269-280. 
Minekus, M., Smeets-Peeters, M., Bernalier, A., Marol-Bonnin, S., Havenaar, R., Marteau, P., Alric, M., Fonty, G. and Huis in't Veld, J.H., 1999. A computer-controlled system to simulate conditions of the large intestine with peristaltic mixing, water absorption and absorption of fermentation products. Applied Microbiology Biotechnology 53: 108-114.

Mitsou, E.K., Panopoulou, N., Turunen, K., Spiliotis, V. and Kyriacou, A., 2010. Prebiotic potential of barley derived $\beta$-glucan at low intake levels: a randomized double-blinded, placebo-controlled clinical study. Food Research International 43: 1086-1092.

Needell, J.C. and Zipris, D., 2016. The role of the intestinal microbiome in type 1 diabetes pathogenesis. Current Diabetes Reports 16: 89.

Nyangale, E.P., Farmer, S., Cash, H.A., Keller, D., Chernoff, D. and Gibson, G.R., 2015. Bacillus coagulans GBI-30, 6086 modulates Faecalibacterium prausnitzii in older men and women. Journal of Nutrition 145: 1446-1452.

Nyangale, E.P., Farmer, S., Keller, D., Chernoff, D. and Gibson, G.R., 2014. Effect of prebiotics on the fecal microbiota of elderly volunteers after dietary supplementation of Bacillus coagulans GBI-30, 6086. Anaerobe 30: 75-81.

Ríos-Covián, D., Ruas-Madiedo, P., Margolles, A., Gueimonde, M., De los Reyes-Gavilán, C.G. and Salazar, N., 2016. Intestinal short chain fatty acids and their link with diet and human health. Frontiers in Microbiology 7: 185.

Rowland, I., Gibson, G., Heinken, A., Scott, K., Swann, J., Thiele, I. and Tuohy, K., 2017. Gut microbiota functions: metabolism of nutrients and other food components. European Journal of Nutrition 57: 1-24.

Salazar, N., Ruas-Madiedo, P., Kolida, S., Collins, M., Rastall, R., Gibson, G. and De los Reyes-Gavilán, C.G., 2009. Exopolysaccharides produced by Bifidobacterium longum IPLA E44 and Bifidobacterium animalis subsp. lactis IPLA R1 modify the composition and metabolic activity of human faecal microbiota in pH-controlled batch cultures. International Journal of Food Microbiology 135: 260-267.
Salvetti, E., Orrù, L., Capozzi, V., Martina, A., Lamontanara, A., Keller, D., Cash, H., Felis, G.E., Cattivelli, L., Torriani, S. and Spano, G., 2016. Integrate genome-based assessment of safety for probiotic strains: Bacillus coagulans GBI-30, 6086 as a case study. Applied Microbiology and Biotechnology 100: 4595-4605.

Sánchez, E., Donat, E., Ribes-Koninckx, C., Calabuig, M. and Sanz, Y., 2010. Intestinal Bacteroides species associated with coeliac disease. Journal of Clinical Pathology 63: 1105-1111.

Schultz, M., Munro, K., Tannock, G.W., Melchner, I., Göttl, C., Schwietz, H., Schölmerich, J. and Rath, H.C., 2004. Effects of feeding a probiotic preparation (SIM) containing inulin on the severity of colitis and on the composition of the intestinal microflora inHLA-B27 transgenic rats. Clinical and Diagnostic Laboratory Immunology 11: 581-587.

Venema, K and Van den Abbeele, P., 2013. Experimental models of the gut microbiome. Best Practice \& Research: Clinical Gastroenterology 27: $115-126$

Venema, K., Van Nuenen, M., Smeets-Peeters, M. and Havenaar, R., 2000. TNO's in vitro large intestinal model: an excellent screening tool for functional food and pharmaceutical research. Nutrition 24: 558-564.

Venkataraman, A., Sieber, J.R., Schmidt, A.W., Waldron, C., Theis, K.R. and Schmidt, T.M., 2016. Variable responses of human microbiomes to dietary supplementation with resistant starch. Microbiome 4: 33.

Walker, A.W., Ince, J., Duncan, S.H., Webster, L.M., Holtrop, G., Ze, X., Brown, D., Stares, M.D., Scott, P., Bergerat, A., Louis, P., McIntosh, F., Johnstone, A.M., Lobley, G.E., Parkhill, J. and Flint, H.J., 2011. Dominant and diet-responsive groups of bacteria within the human colonic microbiota. ISME Journal 5: 220-230.

Williams, C.F., Walton, G.E., Jiang, L., Plummer, S., Garaiova, I. and Gibson, G.R., 2015. Comparative analysis of intestinal tract models. Annual Review in Food Science and Technology 6: 329-350.

Ze, X., Duncan, S.H., Louis, P. and Flint, H.J., 2012. Ruminococcus bromii is a keystone species for the degradation of resistant starch in the human colon. ISME Journal 6: 1535-1543. 
